DOI: https://doi.org/10.24867/08FA11Pajic

\title{
ISPITIVANJE ZAVISNOSTI KOMFORA I BRZINE VETRA NA NIVOU URBANOG BLOKA
}

\section{RESEARCH OF COMFORT AND WIND SPEED DEPENDENCE AT THE URBAN BLOCK LEVEL}

\author{
Milica Pajić, Ivana Bajšanski, Fakultet tehničkih nauka, Novi Sad
}

\section{Oblast - Digitalne Tehnike, Dizajn i Produkcija U ARHITEKTURI IURBANIZMU}

Kratak sadržaj - Izgradnja novih objekata menja mikroklimu u svom okruženju. Jedan od dominantnih faktora koji se smatra kao negativna pojava jeste brzina vetra. Ona na nivou pešaka može imati drastične uticaje. Istraživanje je sprovedeno na bloku u Novom Sadu, koji je u procesu urbanizacije. Računarskom dinamikom fluida, simulacijom vetra, dobijene su brzine, a na osnovu njih analiziran je komfor na nivou pešaka. Cilj istraživanja je poboljšanje spoljašnjeg termalnog komfora i mehaničkog komfora vetra u zavisnosti od aktivnosti pojedinaca.

Ključne reči: algoritam, CFD, PET indeks, komfor, vetar, urbani blok

Abstract - The construction of new buildings changes the microclimate in its environment. Wind speed is a dominant factor and needs to be considered in a situation like this. It can have a huge negative impact on pedestrians. Research is conducted on an urban block in Novi Sad, which is in the process of urbanization. Wind Velocities were obtained from computational fluid dynamics simulation and used in analyzing pedestrian comfort. The aim of the research is to improve the external thermal comfort and the mechanical comfort of the wind depending on the activity of individuals.

Keywords: algorithm, CFD, PET index, comfort, wind, urban block

\section{UVOD}

Brzina vetra na nivou pešaka rezultat je složenog paterna strujanja vetra oko zgrade. Studije komfora pešaka pod uticajem vetra posledično uključuju proučavanje aerodinamike zgrada. Počevši od 1960-ih godina, aerodinamika građevina osigurala je svoje mesto u naučnoj literaturi zahvaljujući izgradnji i korišćenju poboljšanih postrojenja za simulaciju tunela vetra, što je omogućilo tačno simuliranje toka oko zgrada [1].

Svaki novi objekat, koji zauzme svoje mesto u urbanoj matrici, neizbežno menja i mikroklimu u svom okruženju. Ove promene mogu rezultirati kovitlanjem ili povećanom brzinom vetra oko objekta, što može biti nelagodno ili pak opasno. Čini se da naročito veću brzinu vetra negativno doživljavaju ljudi koji žive u umerenim klimama, ali pozitivno doživljavaju u toplijim klimama.

\section{NAPOMENA:}

Ovaj rad proistekao je iz master rada, čiji mentor je bila doc. dr Ivana Bajšanski.
Uzimajući u obzir predviđeni porast temperature usled globalnih klimatskih promena, vetar postaje sve važniji u regionima sa umerenom klimom i trebalo bi ga uzeti $u$ obzir u daljem planiranju.

\subsection{Predmet i cilj istraživanja}

Cilj ovog istraživanja je analiza urbanog bloka, u svrhu poboljšanja spoljašnjeg termalnog komfora pešaka i sprečavanja nepoželjnih efekata vetra. Objedinjavanjem ključnih softvera za modelovanje, analizu podataka i simulaciju vetra dobijaju se najpribližniji uslovi za ovakva ispitivanje, sa nastojanjem da se dobiju rezultati koji će zadovoljiti date uslove.

Posmatrani blok se nalazi u neposrednoj blizini starog gradskog jezgra Novog Sada. Urbana izgradnja i obnova, čiji proces je u toku, obuhvata obnovu mreža infrastrukture, modernizaciju i koordinaciju saobraćaja, uređenje javnih površina i novogradnju.

\subsection{Primenjene metode}

\subsubsection{Parametarsko modelovanje}

U radu je korišćen softver za 3D modelovanje, Rhinoceros i njegov dodatak zasnovan na vizuelnom programskom jezik za parametarsko modelovanje, Grasshopper. $\mathrm{Za}$ potrebe objedinjavanja informacija o vremenskim uslovima i generisanje mapa, korišćeni su alati Elk i Ladybug komponenti.

\subsubsection{Simulacije vetra}

U ovu svrhu korišćena je metoda dinamičkih simulacija, CFD. Kompjuterska dinamika fluida (CFD od eng. Computational Fluid Dynamics) numerički rešava matematičke modele, koji opisuju strujanje fluida.

Razvoj i upotreba CFD-a je postala veoma aktivna grana istraživanja. Modeli postaju sve sofisticiraniji u pogledu numeričkih metoda, mrežne strukture i pristupa modelovanju turbulentnosti. Olakšavajuća okolnost za projektante je svakako razvoj dodatka za Grasshopper Butterfly, koji omogućava konekciju sa CFD softverom kao što je OpenFoam.

\subsubsection{Komparativne analize}

U radu će biti analizirane tri faze urbanizacije gradskog bloka na osnovu mehaničkog i termalnog komfora na nivou pešaka unutarblokovskog prostora. Za ove vrste procene spoljašnjeg komfora zadužen je Ladybug softver. Analizom grafičkih dijagrama i numeričkih pokazatelja, istaknućemo probleme ali i važnost ovakvih analiza na početku dizajna. 


\section{METODOLOGIJA}

\subsection{Analiza lokacije i vremenskih uslova}

Posmatrani blok se nalazi u neposrednoj blizini starog gradskog jezgra Novog Sada. Oivičavaju ga ulice: Kisačka, Jovana Subotića, Đorđa Markovića Kodera i Vuka Karadžića. U poslednjoj deceniji XX veka počeo je novi proces u urbanoj obnovi ovog prostora. Namena je pretežno orijentisana višeporodičnom stanovanju, srednjih gustina naseljenosti, spratnosti $\mathrm{P}+2+\mathrm{Pk}$ i $\mathrm{P}+4+\mathrm{Pk}$, i manjih gustina naseljenosti do $\mathrm{P}+1+\mathrm{Pk}$, dok se poslovanje nalazi u prizemljima stambenih objekata. Odstupanje od ovoga je ugaoni objekat $2 \mathrm{Po}+\mathrm{P}+7+$ zeleni krov.

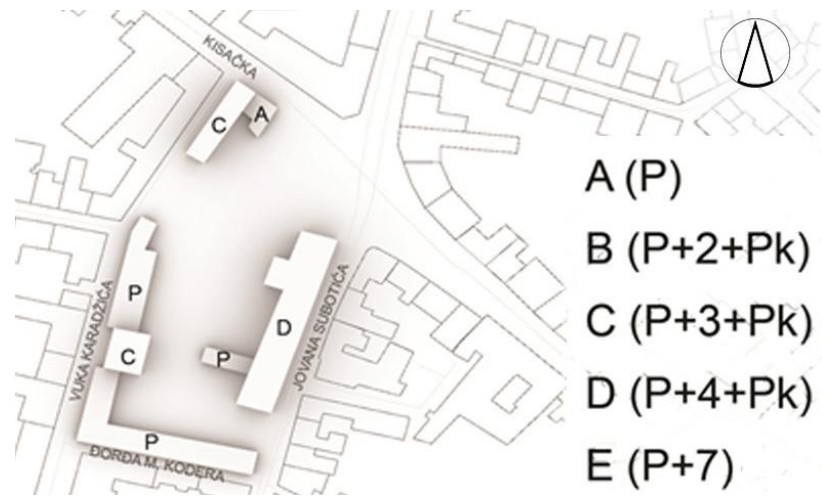

Slika 1. Položaj i spratnost bloka

Prvi korak ka analizi je upotreba Elk skupa alata za generisanje mapa i topografije, koja koristi open source podatke sa OpenStreetMap.org.

Klima je umereno-kontinentalnog tipa sa karakteristikama subhumidne i mikrotermalne klime. Najčešći vetar je iz jugoistočnog i severozapadnog pravca. Ostali pravci vetra nisu posebno značajni.

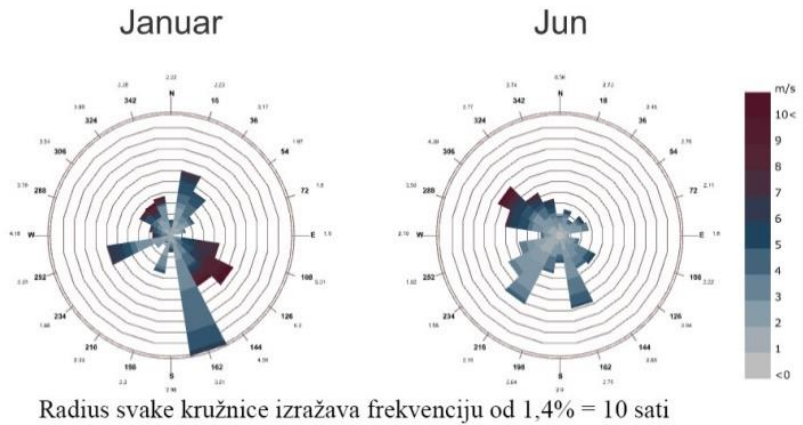

Slika 2. Ruže vetrova

Izabrani smerovi dominantnih vetrova, za zimski i letnji period. Tokom meseca januara jugoistočni vetar brzine $5,42 \mathrm{~m} / \mathrm{s}$, a tokom meseca juna severozapadni vetar brzine $4,60 \mathrm{~m} / \mathrm{s}$.

\subsection{Simulacija vetra}

Algoritam za postavljanje i pokretanje simulacije se $u$ celosti odvija preko Butterfly alatki, koje su zasnovane na objektno orijentisanoj Python biblioteci i ostvaruju vezu sa OpenFoam softverom. OpenFoam je za sada vodeći open source softver, u kom je moguće pokrenuti više naprednih simulacija i modela turbulencije.

Butterfly brzo izvozi geometriju u OpenFoam i pokreće nekoliko vrsta simulacija protoka vazduha, koje su korisne pri dizajnu objekata.

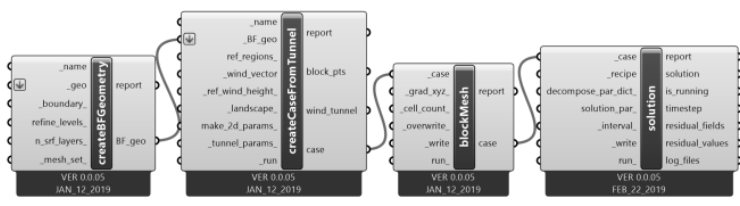

Slika 3. Ključni delovi algoritma za izvršavanje simulacije

Nakon definisanja ulazne geometrije, Butterfly nam omogućava dodatna podešavanja osobina našeg objekta (granice, nivo obrade). Posle ovog koraka postavlja se wind tunnel, na osnovu karakteristika ulazne geometrije. Sva dodatna podešavanja su omogućena ali ne i nužna, kako su već postavljeni početni uslovi unutar Butterfly-a, osim za pravac i brzinu vetra.

Za kreiranje mreže (mesh-a) zadužena je komponenta blockMesh. Nakon ovog koraka obavezno je pokrenuti i snappyHexMesh, koji već kreirani mesh prilagodi ulaznoj geometriji. Rešavanje svakog parametra toka (brzina, pritisak, temperatura) definisano je u centrima svake ćelije mesh-a. Zato tačnost CFD rešenja zavisi od broja ćelija u mreži. Generalno što je veći broj to su precizniji dobijeni rezultati. Optimalni mesh-evi su neuniformni, pa je u područjima velikih promena podela mreže finija, a udaljavanjem od nje postaje grublja. Poslednji korak pred pokretanje simulacije je izbor ,recepta”, koji je u našem slučaju kontinualni nestišljivi tok.

Sve simulacije rađene su na visini od $1.50 \mathrm{~m}$, a geometrija rotirana tako da pravac vetra uvek prati pozitivni smer $\mathrm{Y}$ ose Rhino okruženja.

Ukupno je izvršeno 8 simulacija, za četiri različito formirana bloka (sadašnje stanje, izgradnja ugaonog objekta, po planu regulacije, rešenje nakon analize) i iz dva dominantna pravca vetra.

\subsection{Spoljašnji termalni komfor}

Termalni komfor i njen efekat na ljude se najbolje može razumeti na primeru termalnih indeksa, s obzirom da temperatura vazduha nije koristan indikator. Za ovo istraživanje korišćen je Fiziološki ekvivalent temperature, PET. To je termalni index Definisan je kao temperatura vazduha na kojoj je u tipičnom zatvorenom okruženju, bez vetra i sunčeve radijacije, toplota ljudskog tela izbalansirana sa istom temperaturom kože kao kod spoljašnjih termalnih uslova [2].

Prednosti PET-a su: univerzalnost indeksa nezavisnog od nivoa odevenosti i metaboličke aktivnosti; zasnovan je na termofiziološkim principima; meri se $\mathrm{u}{ }^{\circ} \mathrm{C}$, pa se može lako razumeti; ne oslanja se na subjektivne faktore; koristan je u hladnim i toplim klimama

\subsection{Mehanički komfor pešaka}

Ova komponenta analizira komfor pešaka i sigurnost postojećih i budućih urbanih scenarija. Zasnovana je na Lawsonovom kriterijumu komfora [3].

Za ulazne podatke koristi rezultate CFD simulacije da bi sprovela analizu mehaničkog, ne termalnog komfora.

Nivo komfora pešaka zavisan je od individualne aktivnosti pojedinca. Stoga su Lawsonovi kriterijumi komfora definisani za svaku aktivnost, gde zadata brzina vetra ne sme prelaziti dozvoljenu granicu tokom određenog 
perioda. Kriterijum komfora pešaka se posmatra na visini od $1.5 \mathrm{~m}$ iznad nivoa zemlje. Osim u izuzetnim okolnostima, brzine vetra na nivou pešaka se povećavaju kako se i udaljenost od nivoa zemlje povećava.

\section{REZULTATI}

\subsection{Analiza}

Tokom izvršavanja proračuna unutar OpenFoam-a, rezultati se direktno prikazuju u prozoru Rhino okruženja. Izabrana su tri tipa prikaza rezultata simulacija, vektorski vetra, koloritno vetra, koloritno pritiska.

Pritisak je dobar pokazatelj ispravnosti naše simulacije, pa je pogodno posmatrati ga dok se ista proračunava i prekinuti je ako smatramo da postoje nelogičnosti. Na mestima gde je pritisak visok (tamnija mesta) vetar bi trebao imati manju brzinu, i obrnuto, nizak pritisak nagoveštava ubrzanje.

Vektorski način prikazivanja pogodan je, jer se lako uočava kretanje vetra i njegova brzina nakon kontakta sa objektima. Poslednji prikaz je takodje vezan za brzinu vetra, s tim što se jasnije vide kritična mesta pojave ubrzanja u kontaktu sa geometrijom.

Analizom svih konfiguracija postalo je jasnije na kojim mestima i zbog čega se javlja kovitlanje i ubrzanje vetra.

Posebno je problematičan pravac vetra sa jugoistoka, za sve slučajeve konfiguracije. Kako ovaj vetar duva pretežno u zimskom periodu, njegov prodor u blok bi trebao biti potpuno ograničen. Logičan sled je bio da će treća simulirana konfiguracija dati najbolje rešenje, kako je blok u ovom slučaju potpun zatvoren, osim malog parkovskog prostora na severu. Ovaj blok ima najbolje rezultate, ali se javljaju drugi problemi. U ovom slučaju vetar pri kontaktu sa objektom, menja smer, izjednačavajući pritisak, završava u unutrašnjosti bloka sa ubrzanjem. Kako je blok potpuno zatvoren u tom delu, vetar ostaje zarobljen, kovitla i stvara nebezbedan prostor. (Slika 4. Drugi red)

Problemi se javljaju i pri udaru vetra na uglovima zgrada. Kako je planom detaljne regulacije za blok namenjena potpuna zatvorenost, osim parkovskog prostora na severu bloka, posvećena mu je posebna pažnja.

Uski prolazi između visokih zgrada stvaraju nepovoljne uslove, naročito ako su namenjeni za dugotrajan boravak, sedenje, odmaranje (kao što je slučaj ovde).

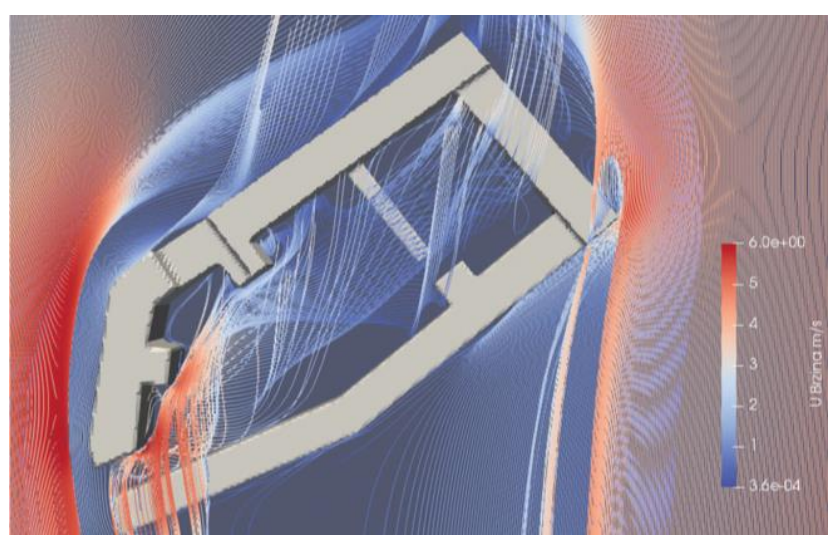

Slika 5. Paraview 3D prikaz toka

Nekada se na osnovi sa brzinama vetra, ne može lako uočiti šta je dovelo do ubrzanja istog, stoga nam 3D pogled sa Paraview softverom pokazuje tačnu putanju linije vetra i uzrok promene u brzini.

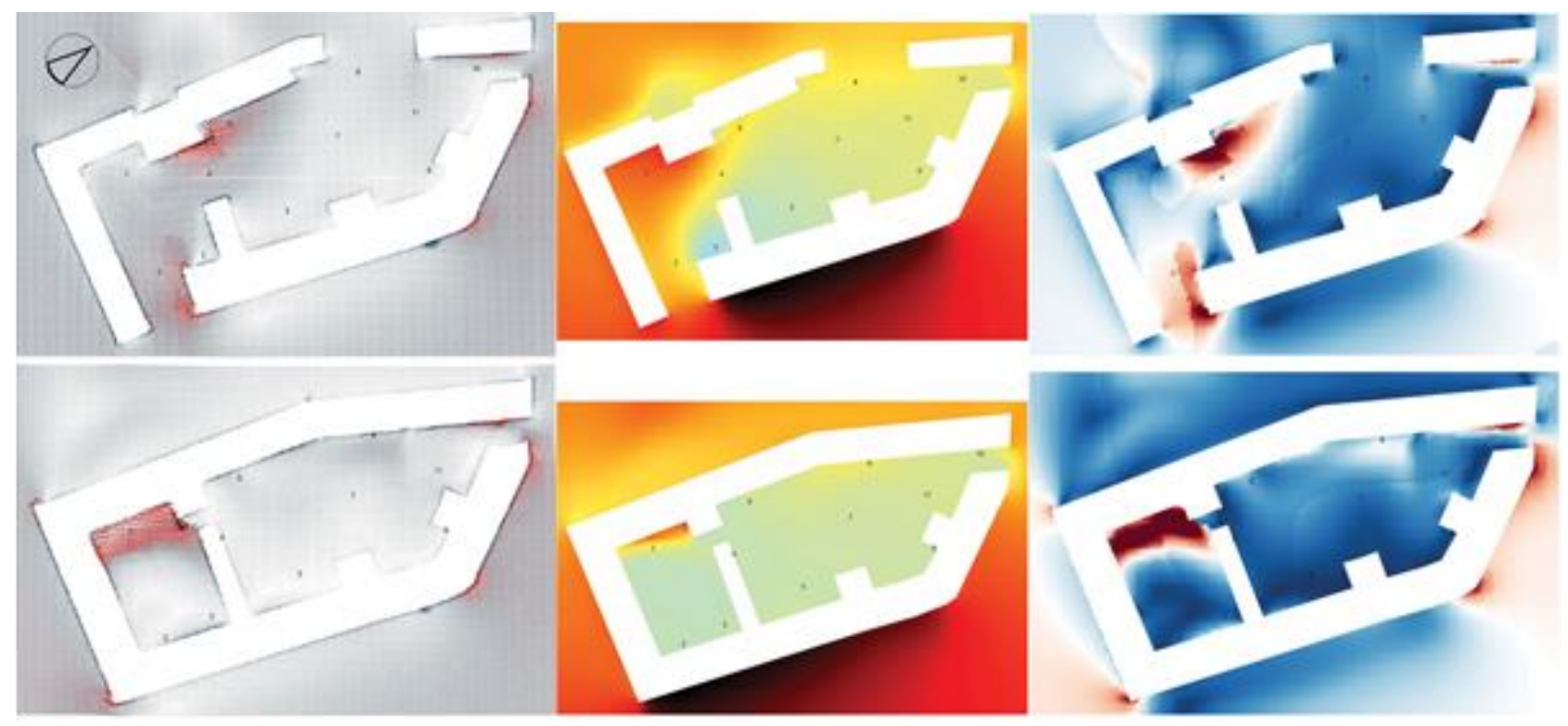

Slika 4. Rezultati simulacija

\subsection{Poboljšanje termalnog i mehaničkog komfora}

Termalni komfor unutarblokovskog prostora, posmatran je za 11 različitih pozicija, radi lakšeg razumevanja uticaja vetra na ugodnost. Prikazan je u $\mathrm{C}^{\mathrm{o}}$ što takođe pojednostavljuje upotrebu.
Na primerima posmatranim tokom meseca juna, jasno se vidi da treća konfiguracija ima najveći procenat, tj temperatura na pozicijama je u okvir od $18-23 \mathrm{C}^{\mathrm{o}}$, što je po Lawsonovoj skali neutralno stanje/ komforno. 
Za mesec januar nije bilo pogodno koristiti procenat da se pokaže najbolje rešenje, jer je ovde zimski period uvek ispod $0 \mathrm{C}^{\mathrm{o}}$. Lawsonovi kriterijumi sve temperature ispod 4 $\mathrm{C}^{\mathrm{o}}$ ubrajaju u kategoriju ekstremno hladnog stresa. Posmatrana je svaka pozicija posebno da bi se uočili nedostaci.

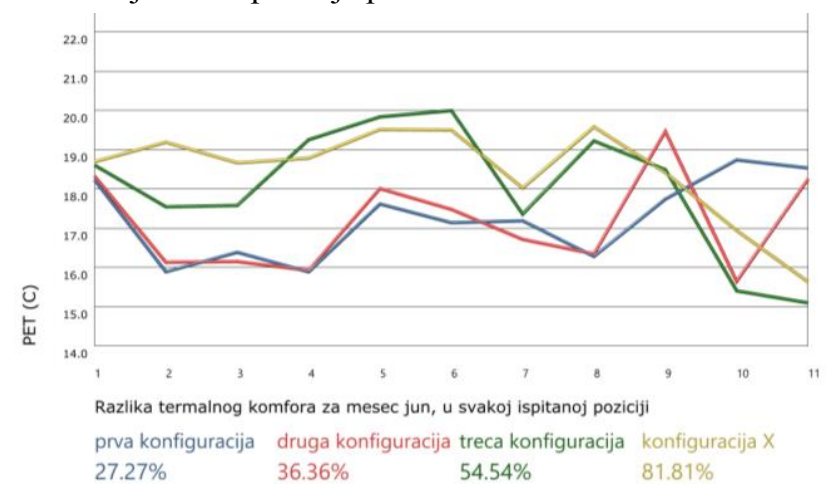

Slika 6. Fiziološki ekvivalent temperature

U izabranoj konfiguraciji bloka, otklonjeni su svi glavni problemi uočeni na ispitanim slučajevima. Kako je urbanizacija i razvijanje Novog Sada neizbežna pojava, sa ovim rešenjem sačuvana je planirana zgrada $\mathrm{P}+7$ i parkovska površina pored nje. Veliki problem koji je nastajao u parku zbog uskog prolaza između dve zgrade, rešen je uvlačenjem fronta i proširivanjem parka ka ulici Vuka Karadžića. Front ulice Jovana Subotića i danas većim delom čine objekti spratnosti $\mathrm{P}+4+\mathrm{Pk}$, što je zadržano i prošireno i na ulicu Đorđa Markovića Kodera. Objekat B sa samo jednim spratom, nije više na udaru jugoistočnog vetra, pa ne dolazi do promene pravca istog ka pešacima, čineći prostor nelagodnim. Analiza bezbednosti pešaka nije pokazala ni jedan nebezbedan prostor.

\section{ZAKLJUČAK}

Rešavanje zapaženih problema nakon izgradnje objekata može biti teško, skupo i ne toliko efikasno.

Predstavljena je korist proračuna CFD simulacija u svrhu procene komfora i sigurnosti pešaka na primeru bloka u procesu urbanizacije.

Donešeni su sledeći zaključci:

CFD predstavlja vodeći alat za ispitivanje kritičnih uticaja vetra u interakciji sa izgrađenom sredinom, sa stanovišta komfora pešaka.

Izgrađeni objekti, na maloj udaljenosti, značajno deformišu tok vetra, koji je mnogo složeniji nego što se pretpostavljalo.

Zavisnost komfora od brzine i turbulencije vetra je velika, $\mathrm{i}$ ispoljava se primetno u urbanizaciji gradskih okruženja. Naglašava se uzimanje u obzir uticaja vetra na formiranje budućeg razvoja grada.
Numeričko modelovanje sa CFD-om svakako predstavlja iskorak ka alternativnim studijama vetra. Prednost je $\mathrm{u}$ tome što je manje vremena potrebno i jeftiniji je od fizički modelovanih tunela vetra i direktno daje detaljni protok vetra u svakoj tački oko proučavane konfiguracije.

Sa daljim razvojem tehnologije biće omogućeno posmatranje celokupnog kompleksnog okruženja sa svim relevantnim parametrima uračunatim u proces proračuna, bez velikog opterećenja na posedovani hardver. Stoga je veoma bitno dodatno olakšati i pojednostaviti uzimanje $u$ obzir svih ključnih parametara proračuna CFD simulacija kao i analize komfora.

\section{LITERATURA}

[1] B. Blocken, W. Janssen, T. Van Hoof, Use of CFD simulations to improve the pedestrian wind comfort around a high-rise building in a comlex urban area. Eindhoven University of Technology, Netherlands, 2013

[2] P. Höppe. The physiological equivalent temperature a universal index for the biometeorological assessment of the thermal environment. International Journal of Biometeorology, 1999

[3] Lawson, T.V. The wind environment of buildings: a logical approach to the establishment of criteria. Report No. TVL 7321, 1973

[4] I. Bajšanski, Algoritam za poboljšanje termalnog komfora u urbanoj sredini, Univerzitet u Novom Sadu, Fakultet Tehničkih Nauka, Novi Sad, 2016

[5] Skupština grada Novog Sada, Plan detaljne regulacije blokova oko ulice Vojvode Bojovića u Novom Sadu, Republika Srbija, 2018

\section{Kratka biografija:}

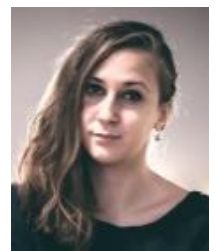

Milica Pajić rođena je u Šapcu 1992. godine. Master rad na Fakultetu tehničkih nauka iz oblasti Digizalnih tehnika, dizajna i produkcije u arhitekturi i urbanizmu odbranila je 2019.god.

kontakt: milicapajicvl@gmail.com

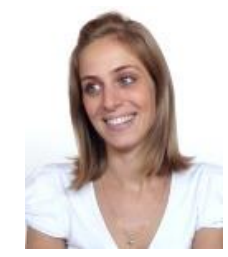

Ivana Bajšanski rođena je u Vrbasu 1986. godine. Doktorirala je na Fakultetu tehničkih nauka 2016. god., a od 2017. je u zvanju docenta. Oblast interesovanja joj je digitalni dizajn u arhitekturi i urbanizmu. 